\title{
An Overview of Biodegradation of LNAPLs in Coastal (Semi)-arid Environment
}

\author{
Brijesh Kumar Yadav • S. Majid Hassanizadeh
}

Received: 22 September 2010 / Accepted: 14 January 2011 /Published online: 22 February 2011

(C) The Author(s) 2011. This article is published with open access at Springerlink.com

\begin{abstract}
Contamination of soil and water due to the release of light non-aqueous phase liquids (LNAPLs) is a ubiquitous problem. The problem is more severe in arid and semi-arid coastal regions where most of the petroleum production and related refinery industries are located. Biological treatment of these organic contaminated resources is receiving increasing interests and where applicable, can serve as a cost-effective remediation alternative. The success of bioremediation greatly depends on the prevailing environmental variables, and their remediation favoring customization requires a sound understanding of their integrated behavior on fate and transport of LNAPLs under site-specific conditions. The arid and semi-arid coastal sites are characterized by specific environmental extremes; primarily, varying low and high temperatures, high salinity, water table dynamics, and fluctuating soil moisture content. An understanding of the behavior of these environmental variables on biological interactions with LNAPLs would be helpful in customizing the bioremediation for restoring problematic sites in these regions.
\end{abstract}

B. K. Yadav $(\bowtie)$

Department of Civil Engineering, Indian Institute of Technology Delhi, Hauz Khas, New Delhi 110016, India

e-mail: brijeshy@gmail.com

S. M. Hassanizadeh

Environmental Hydrogeology Group, Faculty of Geosciences, Utrecht University, Budapestlaan 4, P.O. Box 80021, 3508 TA Utrecht,

The Netherlands
Therefore, this paper reviews the microbial degradation of LNAPLs in soil-water, considering the influences of prevailing environmental parameters of arid and semiarid coastal regions. First, the mechanism of biodegradation of LNAPLs is discussed briefly, followed by a summary of popular kinetic models used by researchers for describing the degradation rate of these hydrocarbons. Next, the impact of soil moisture content, water table dynamics, and soil-water temperature on the fate and transport of LNAPLs are discussed, including an overview of the studies conducted so far. Finally, based on the reviewed information, a general conclusion is presented with recommendations for future research subjects on optimizing the bioremediation technique in the field under the aforesaid environmental conditions. The present review will be useful to better understand the feasibility of bioremediation technology, in general, and its applicability for remediating LNAPLs polluted lands under aforesaid environments, in particular.

Keywords Bioremediation - Arid and semi-arid environments $\cdot$ LNAPL $\cdot$ Coastal region .

Biodegradation

\section{Introduction}

Soil and water pollution by petroleum-derived contaminants, commonly referred to as dense and light non-aqueous phase liquids (DNAPL and LNAPL, respectively) is a growing problem, particularly in 
arid and semi-arid coastal regions due to population growth and developments. These volatile organic liquids are often toxic or carcinogenic and can sparingly dissolve in water (Zhang et al. 1998a, b). The aqueous solubility of these contaminants is low but large enough to seriously degrade water quality in the soil. When released to the (sub)-surface, NAPLs move downward through the soil. LNAPLs are generally retained on top of the water table, while DNAPLs penetrate the saturated zone and migrate downward till they are retained by an impermeable layer (USEPA 2006). Both cases present a potential threat to the receiving environment. However, the regions having complex dynamic environmental conditions seem more vulnerable to LNAPLs threats because of wide coverage and mobilization of small spillages of LNAPLs.

The LNAPLs migrate laterally as an immiscible phase in a direction roughly parallel to the slope of the water table (Marinelli and Durnford 1996). Transport of dissolved LNAPL in the subsurface depends mainly on concentration gradients in soil water and air phases and takes place by convection and diffusion. In convective transport in water phase, the dissolved LNAPLs are carried as water moves due to pressure gradient. Similarly, convective transport in the soil gas phase takes place when the soil gas moves as a result of several processes like changes in gas phase density due to heating or cooling, water table fluctuations, air sparging, or gas production (Mercer and Cohen 1990). Upward movement of dissolved LNAPLs can also take place as a result of vertical movement of soil water induced by evapotranspiration at the soil surface (Zhang et al. 1998a, b; Yadav et al. 2009). In a saturated zone, the dissolution from the pure LNAPL phase to the groundwater is considered the main limiting factor of the contaminant transport process (Abriola 1989; Powers et al. 1991). On the other hand, diffusion through the gas phase is considered by far the predominant route of transport in unsaturated part (Marrin and Kerfoot 1988).

Thus, LNAPL release in arid and semi-arid coastal regions, which are characterized by dynamic environmental conditions like water table fluctuation and large temperature variability, poses a severe threat to the receiving soil, air, and water resources. Remediation of these polluted sites has established the need to develop a wide variety of innovative physical, chemical, and biological techniques to remove these organic pollutants without causing further ecological damage. The common physical measures for cleanup of LNAPLs spills are physical containment, wiping, booming and skimming, mechanical removal, water flushing, and sediment relocation (Zhu et al. 2004). Use of dispersants as a chemical method is quite common in some countries but not in others due to the disagreement about their effectiveness and longterm environmental toxicity concerns (USEPA 1998). The potential for this application may increase with the recent production of non/less toxic chemical dispersants. The aforementioned methods often are the first response option, and they rarely achieve complete cleanup of LNAPLs spills. There are secondary techniques like carbon adsorption, electro remediation, air sparging, filtration, and adsorption by zeolites (Daifullah and Girgis 2003; Yang et al. 2005; Ranck et al. 2005) as well as chemical oxidation, and photo-catalysis (Mascolo et al. 2007).

One of the most promising secondary treatment options is bioremediation. This is because of its low cost and the fact that it is less intrusive to the polluted site and environmentally benign compared with the above-said conventional techniques (Juhasz et al. 2000; Farhadian et al. 2008). Introduction of hydrocarbons drive the existing soil microorganisms to adapt to the changed environment. The microorganisms begin to degrade the contaminants by using them as an energy source, ultimately cleaning the polluted environment (Fiorenza and Ward 1997). With increasing numbers of successful cleanup sites, this biological remediation, alone or in combination with other treatment techniques, has gained an established place as a land restoration method. The key role in bioremediation is played by microorganisms which are very diverse in nature and comprised of bacteria, fungi, and yeast. In the following, we will use the term microorganism interchangeably as microbes, degraders, and microbiota without any explicit distinction.

The degree of bioremediation success depends on a number of factors, including the level and properties of targeted pollutants, site properties, and microbial and environmental limitations of bioremediation (Yang et al. 2009). Natural or intrinsic bioremediation has been occurring since the beginning of life on earth, but the process is relatively slow, and it takes more time for removing hydrocarbons from the polluted sites. Therefore, in engineered bioremediation, attempts are made to speed-up the naturally occurring biodegradation 
through customizing local environmental conditions either by (1) bioaugmentation, in which microbes are added or by (2) biostimulation, i.e., providing/ maintaining the favorable conditions for growth of the soil microorganisms (Norris et al. 1994; Allard and Neilson 1997; Mikszewski 2004; USEPA 2006). The technique of bioaugmentation may have some potential in the treatment of specific NAPL components, isolated spills in confined areas, or certain environments where degraders are deficient. But, in many field trials, this technique has shown little benefit for the remediation of the hydrocarbons, as reported by Zhu et al. (2004).

On the other hand, biostimulation has been proven to be a promising bioremediation technique to treat certain LNAPL-contaminated sites aerobically (Rosenberg et al. 1992; Venosa et al. 2002). As said before, the key factors for the successful implementation of biostimulation are: to maintaining the optimal nutrients level and regulating the site prevailing environmental parameters in a favorable range required for the growth of microbes. Extensive research has been conducted to enhance degradation of hydrocarbons by maintaining optimal nutrients condition under constant environmental parameters. However, the effectiveness of this technology is rarely demonstrated under site-specific varying environmental extremes. Therefore, a review of the art pertaining to bioremediation of hydrocarbon-polluted sites under important environmental extremes is presented here with special emphasis on arid and semi-arid coastal regions polluted with LNAPLs.

\section{LNAPL's Metabolism and Associated Kinetics}

In biodegradation of LNAPLs, the pollutants act as carbon source, either through oxidative or reductive processes (Lin et al. 2002). Microbes also need nutrients, electron acceptors, and growth-favoring environmental conditions to perform the remediation process (Fiorenza and Ward 1997; Van Hamme et al. 2003). The electron transfers occurring during these biochemical reactions release energy and is further utilized for microbial growth and cell maintenance. Thus, the degradation rate of these organic pollutants can be accelerated by maintaining the optimal concentration of electron acceptors and nutrients in addition to regulating the environmental conditions of a targeted site (Van Hamme et al. 2003).
Under aerobic conditions, oxygen is the main electron acceptor, and bioremediation typically proceeds through oxidative processes to render LNAPLs either partially oxidized to less complex by-products or complete oxidation/mineralization to $\mathrm{CO}_{2}$ and $\mathrm{H}_{2} \mathrm{O}$ (Wise et al. 2000). Therefore, in saturated zones, the aerobic biodegradation of LNAPLs is often limited by dissolved oxygen concentration, hence, techniques such as air sparging, bioventing, and supply of oxygen-releasing compounds like $\mathrm{H}_{2} \mathrm{O}_{2}$ and $\mathrm{MgO}_{2}$ are used to compensate the utilized oxygen (Morgan and Watkinson 1992; Johnston et al. 1998). LNAPLs can also be metabolized under anaerobic conditions, provided sufficient electron acceptors like sulfate, iron, or nitrate is present (Cunningham et al. 2001). In methanogenic bioremediation, the hydrocarbons are converted to methane, carbon dioxide, and traces of hydrogen (Rockne and Reddy 2003). Another type of anaerobic bioremediation is reductive dehalogenation where the contaminants are reduced by removal of halogens such as chlorine or nitro groups. Typically for LNAPLs, the most rapid and complete degradation is brought aerobically and hence preferred in engineered bioremediation (Riser-Roberts 1998). Mostly, aerobic degradation related literature is mentioned below, and a brief coverage of anaerobic degradation is meant for completeness of the topic.

In biodegradation of LNAPL, a series of stoichiometries (known as biodegradation pathways) takes place, as complex substances are transformed into simpler daughter compounds. For most LNAPLs, these daughter compounds are relatively stable and less toxic than their parent hydrocarbons. Though the precise pathways of LNAPLs oxidation is debated in the literature (Farhadian et al. 2008), transformations likely to occur stepwise from end-carbons producing alcohols, aldehydes, and fatty acids in sequence (Singer and Finnerty 1984; Tsao et al. 1998; Andreoni and Gianfreda 2007). Furthermore, the biodegradation of LNAPLs occurs at specific rates which are function of prevailing environmental factors such as availability of nutrients, oxygen concentration, $\mathrm{pH}$ value, concentration and bioavailability of contaminants, physical and chemical characteristics, and the pollution history of the contaminated site. Therefore, a thorough understanding of hydrocarbons degradation rate kinetics under simplified conditions is a prerequisite for discussing biodegradation of LNAPL-polluted coastal regions in arid and semi-arid environments. 
A general expression of hydrocarbons depletion in soil, in which only microbial densities and the contaminant concentration determine the degradation kinetics, can be written as (Lyman et al. 1992):

$-\frac{d C}{d t}=\mu_{\max } C \frac{\left(C_{0}+X_{0}-C\right)}{\left(K_{S}+C\right)}$

where $\mu_{\max }$ is the maximum growth rate, $C$ is the contaminant concentration at time $t, C_{0}$ is the initial contaminant concentration, $X_{0}$ corresponds to the contaminant required to produce initial microbial density, $K_{\mathrm{s}}$ is the half saturation constant also known as growth limiting concentration. The above equation reflects a linear effect of changes in microbial density as well non-linear effect of changes in contaminant concentration on the rate of contaminant degradation. Furthermore, different simplified degradation kinetic models can be approximated considering extreme ratios of initial contaminant concentration $\left(C_{0}\right)$ to $K_{\mathrm{s}}$ or initial microbial densities $\left(X_{0}\right)$ to $C_{0}$ in Eq. 1. Five special cases of this expression are listed in Table 1.

In zero-order kinetics, the rate of depletion of contaminant is taken as a constant irrespective of the contaminant concentration in soil water at a particular time. This kinetics represents an oversimplification of the LNAPLs bioremediation in soils and is mostly used for drug degradation in suspensions where the rate of degradation is related to the drug concentration in solution rather than to its total concentration in product (Lieberman et al. 1998).

The first-order or linear kinetics model assumes the rate of contaminant degradation proportional to the LNAPL concentration at a particular time. This kinetics is often appropriate for simulating NAPLs biodegradation in aquifers (Seagren et al. 1994; Clement et al. 2000) due to mass transfer limitation during contaminant diffusion from soil water to microbes which are mostly attached to the aquifer solids (Alvarez and Illman 2006; Simoni et al. 2001). Moreover, a LNAPL concentration below the corresponding Monod's half saturation coefficient $\left(K_{\mathrm{S}}\right)$ reduces the degradation kinetics to the first-order one. Clearly, this biodegradation kinetics is limited to soils having low contaminant concentrations and is therefore not appropriate for severely polluted variably saturated soils.

The first-order kinetics is used popularly with groundwater modelers where the contaminant concentration is relatively low due to mass transport limitations. In this modeling approach, uncertainties in the aquifer parameters like sorption, dispersion, and biodegradation are lumped together in decay coefficient which is used as the main calibration parameter (Wiedemeier et al. 1999). However, the decay coefficient is not necessarily a constant parameter and may vary in time and space (Merchuk and Ansejo 1995) and therefore, should not be extrapolated from the literature. So, considerable care must be taken in its determination to avoid over- or under-prediction of actual LNAPL biodegradation rate and plume behavior.

The most popular kinetics for characterizing LNAPLs biodegradation is the hyperbolic equation proposed by Monod (1949) and referred as Monod or Michaelis-Menten kinetics. The Monod kinetics can describe degradation rates ranging from zero-order to the first-order kinetics with respect to the target contaminant concentration. Therefore, it is also termed as a biphasic kinetics model. For $C<<K_{s}$, this kinetics reduces to the linear model and for $C>>K_{s}$, it approaches to the zero-order kinetics. Thus, the Monod kinetics uniquely represents the degradation rate of a specific LNAPL compound under varying concentrations and seems most rigorous of the three mentioned models. The logarithmic model lacks a horizontal asymptote as time becomes large and the logistic model is only occasionally encountered in microbiological literature (Slater 1979) but it is well known in ecology (Odum 1971).

These kinetic expressions are applicable to soils having non-limiting nutrients, absence of mass transfer limitations, optimal soil moisture content, and constant
Table 1 Summary of vari ous kinetic models used for the description of biodegradation

\begin{tabular}{llll}
\hline Kinetics model & Condition & Equation & Rate constant \\
\hline Constant or zero-order & $X_{0} \gg>C_{0} ; C_{0}>>K_{\mathrm{S}}$ & $-\partial C / \partial t=k_{0}$ & $k_{0}=\mu_{\max } X_{0}$ \\
Linear or first-order & $X_{0} \gg>C_{0} ; K_{\mathrm{S}}>C_{0}$ & $-\partial C / \partial t=k_{1} C$ & $k_{1}=\mu_{\max } X_{0} / K_{\mathrm{S}}$ \\
Monod or Michaelis-Menten & $X_{0} \gg>C_{0}$ & $-\partial C / \partial t=k_{\mathrm{m}} C /\left(K_{\mathrm{S}}+C\right)$ & $k_{m}=\mu_{\max } X_{0}$ \\
Logistic & $K_{\mathrm{S}}>>C_{0}$ & $-\partial C / \partial t=k_{\mathrm{l}} C\left(C_{0}+X_{0}-C\right)$ & $k_{1}=X_{0} / K_{\mathrm{S}}$ \\
Logarithmic & $K_{\mathrm{S}}>C_{0}$ & $-\partial C / \partial t=k\left(C_{0}+X_{0}-C\right)$ & $k=\mu_{\max }$ \\
\hline
\end{tabular}


physic-chemical factors (i.e., temperature, salinity, and $\mathrm{pH})$. Out of these factors, some may affect the rate of substrate uptake by microbial assemblage and others may alter the rate of contaminant transport/supply to the microorganisms (Merchuk and Ansejo 1995; Bosma et al. 1997). As constant optimal conditions are rarely found in field, the basic degradation kinetics should consider the prevailing site-specific varying environmental parameters.

\section{Prominent Environmental Factors}

Several environmental factors, in particular, oxygen supply, soil moisture, $\mathrm{pH}$, nutrients, temperature, and redox potential, have been identified as possible determinants of successful bioremediation (Sims et al. 1993). Among these, soil moisture and temperature variations along with groundwater table dynamics seem most crucial for biodegradation feasibility of polluted semi-arid and arid coastal regions (Yadav et al. 2010). The integrated influences of these variables often result in complex and dynamic flow, transport, and biogeochemistry in these polluted regions.

\subsection{Biodegradation in Variably Saturated Soils}

The variation of soil moisture content, due to the changing soil-atmosphere flux and water table dynamics, substantially affects the fate and transport of LNAPL in polluted sites (Davis and Madsen 1996; Andre et al. 2009). In particular, biodegradation process is strongly affected by the soil moisture content. The variation in soil moisture content remarkably affects the total water potential (sum of soil matric and solute water potentials) which is a measure of the energy state of water in soils. The soil water potential affects the supply of oxygen as well as aqueous phase nutrients to microbiota through its relationship to water film thickness (Taylor and Ashcroft 1972). The soil water potentials near the land surface frequently go beyond -10 bars in arid and semi-arid environments and may cause microbial cellular water loss (desiccation stress). Some organisms are capable of metabolic activity at even lower water potentials such as -80 bars (Kieft et al. 1987; Griffiths et al. 2003), but in general, microbial degradation rates are highest at soil water potential between 0 and -1 bar (Sommers et al. 1981). Thus, the soil water potential has direct impacts on biodegradation of LNAPLs and may be the most important environmental factor influencing degraders in arid and semi-arid regions.

In other words, distribution of water and air has direct effects on solute transport and soil microbial processes responsible for degradation of organic pollutants. The soil microbes need both oxygen and water to perform the degradation (Lyman et al. 1992; Meikle et al. 1995). Furthermore, diffusion of nutrients and by-products during the breakdown process are directly influenced by soil water/air ratio (Konopka and Turco 1991). The low soil moisture content results in greater air-filled porosity, which should improve oxygen mass transfer to LNAPL-degrading microbial assemblage. However, there is likely to be a trade-off between improved oxygen availability and the detrimental influences of scarce soil moisture content (Arora et al. 1982; Alvarez and Illman 2006). Microbial activity is diminished due to insufficient moisture content necessary for microbial metabolism and for nutrients bioavailability (CONCAWE 1998). The soil moisture availability also affects the LNAPLs bioavailability which in turn influences the microbial populations and their activities (Airoldi 1999). Thus, the water/air ratio has an optimum value for site-specific conditions; extremes like very wet or dry soil conditions considerably reduce the biodegradation rates of LNAPLs.

The dependency on soil water content for biodegradation of LNAPLs is compound and soil-specific (Holman and Tsang 1995). Moisture is a critical parameter for degradation of small-chain aromatic hydrocarbons, and it has been observed that degradation is considerably greater at $80 \%$ than at $40 \%$ of soil field capacity. Holman and Tsang (1995) determined that a water content of $50-70 \%$ of field capacity was optimum for biodegradation of aromatic hydrocarbons to proceed at maximum rate. For simple monoaromatic and diaromatic hydrocarbons, such as toluene and naphthalene, a first-order kinetic model provided a good fit to mineralization data over a range of soil moisture content. However, for larger polycyclic aromatic hydrocarbons, such as phenanthrene and anthracene, their model provided a good fit only at soil water content below 50\%. Since longchain aliphatic hydrocarbons have a low solubility, their mineralization is little affected by the soil water content. 
Soil texture and structure determine the moisture holding capacity of a polluted site, which in turn affects the biodegradation rate of LNAPLs. The amount of soil water held between field capacity and the permanent wilting point is utilized by plants and soil microbial and chemical reactions and is known as bioavailable water. Soils with a mixture of pore sizes, such as loam, hold more bioavailable water and significant oxygen. Large pore spaces are less hospitable environments for microorganisms whereas the smaller pores retain water for longer time (Papendick and Campbell 1981; Turco and Sadowsky 1995).

The microbial species composition of the soil is regulated mainly by water availability, which in turn is governed essentially by the energy of the water in contact with the soil or LNAPL. When soil moisture becomes limiting, many microorganisms form spores, cysts, or other resistant forms, while many others die as a result of desiccation (JRB 1984). On the other hand, soil fungi can tolerate dry soil conditions but do not grow well if the soil is wet (Harris 1981; Riser-Roberts 1998). The motility of soil microorganisms can be affected by pore size distribution and soil moisture content (Lyman et al. 1992). The motility is negligible below -0.1 bar (Griffin 1981) which is quite common in arid and semi-arid environments.

Likewise, the mass transfer of LNAPLs through soils is dependent on soil water content (English and Loehr 1991). At high soil moisture contents, LNAPLs mass transfer is impeded due to reduced air-filled porosity and partitioning of LNAPLs into soil water (Papendick and Campbell 1981). However, LNAPL molecules may be retarded by adsorption onto organic and/or mineral components of soil solids when airfilled porosity increases at low water contents (Petersen et al. 1994). In typical unsaturated soils, the solute diffusion rate is less than $50 \%$ of the rate under saturated conditions if the matric water potential is beyond -0.1 bar (Griffin 1981). In addition, the indirect effect of unsaturated conditions in soils is to reduce microbial access to solutes, including essential nutrients. This physical separation of microbes from nutrients may induce states of relative inactivity and long-term starvation in the microbes of unsaturated sites and may severely limit rates of biodegradation of organic pollutants in contaminated lands. Moreover, soil temperature is also modified by the changing soil moisture content.
Most studies on biodegradation of organic pollutants, including LNAPLs, have been conducted at or near-optimal soil moisture conditions. The importance of soil moisture in regulating microbial activities and their capacity to degrade the pollutants has been studied by Pramer and Bartha (1972), Dibble and Bartha (1979), Bossert et al. (1984), Huddleston et al. (1985), Ryan et al. (1983), Thomas et al. (1993), Davis and Madsen (1996), Harms (1996), Holden et al. (1997), Holden et al. (2001), and Chen et al. (2007). Most of these studies have suggested an optimal level of soil moisture content suitable for biodegradation of different hydrocarbons. For instance, Pramer and Bartha (1972) showed that biodegradation of simple or complex organic materials in soil is commonly greatest at $50 \%$ to $70 \%$ of the soil field capacity. Dibble and Bartha (1979) report optimal biodegradation at soil moisture content in between $30 \%$ and $90 \%$ of soil field capacity. Similarly, soil moisture around $35 \%$ to $50 \%$ of field capacity was found to accelerate microbial respiration in a JP-4-contaminated soil by Dupont et al. (1991).

In column experiments with 2,4 dichlorophenoxyacetic acid, the decreased availability of oxygen under saturated conditions was considered to be responsible for the declined degradation rates (Estrellea et al. 1993). Harms (1996) demonstrated that the degradation rates of a LNAPL-polluted porous medium depend on the effective diffusivity which is directly related to the soil water content. It was proposed that the effective diffusivities of the LNAPL and the spatial distribution of substrates and bacteria are the main determinants of final cell numbers and, consequently, final degradation rates. Furthermore, the need for moisture was demonstrated in the efforts to remediate oil-polluted Kuwaiti desert soil by Radwan et al. (1995). In another instance, a subsurface drip irrigation system was used to increase soil moisture during bioventing of dry sandy soils contaminated with gasoline, JP-5 jet fuel, and diesel fuel to a depth of $24 \mathrm{~m}$ (Zwick et al. 1995). Holden et al. (1997) quantified the effects of matric as well as solute water potential on toluene biodegradation by Pseudomonas putida bacterial strain growth. They concluded that slightly negative matric potentials $(-0.25$ bar $)$ was favorable for the bacterial growth, but more negative water potentials resulted in slower growth. Furthermore, the LNAPL utilization rate was unaffected by solute potential. Later, Holden et al. (2001) showed 
that biodegradation rate of toluene decreased with decreasing water potential down to -1.0 bar and was undetectable at -1.5 bar.

Thus, soil moisture content profoundly influences composition, motility, survival, and activities of microorganisms responsible for degradation of LNAPLs. Also, the water content affects transport of soil solutes, which in turns affects the microbial accessibility to substrate and essential nutrients. Therefore, an understanding of the mechanisms through which soil moisture affect LNAPLs biodegradation combined with other environmental factors like temperature, soil characteristics, water table dynamics, and salinity is needed for efficient application of bioremediation in arid and semi-arid coastal sites.

\subsection{Water Table Dynamics and LNAPLs Behavior}

The coastal sites, including arid and semi-arid regions, are mostly characterized by a shallow unconfined aquifer with fluctuating water table (Lee et al. 2001). The water table elevation and capillary fringe vary due to the changing water stage in coastal water bodies (i.e., estuaries or rivers, coastal bays) and by ocean tides. Diurnal stage fluctuations induce a rapid and significant response in the surrounding land mass over shorter distances and damp at further distances (Williams and Oostrom 2000). Seasonal fluctuations may occur when water uptake by coastal vegetation, evaporation, surface recharge, and groundwater withdrawal vary over the course of the year (Zhang et al. 1998a,b; Yadav et al. 2009). Variations in water table can also occur over longer time if average groundwater withdrawal/discharge rates exceed the average water recharge rates or vice versa (Lakshmi et al. 1998).

The water table dynamics can greatly affect the distribution, particularly in the vertical direction and degradation process of LNAPLs (Mercer and Cohen 1990) in addition to the soil moisture and temperature distribution. The LNAPLs floating near the water table are susceptible to smearing up and down due to the water table fluctuations. The LNAPLs move downward as the water level falls, leaving behind a residual fraction in the vadose zone in the form of isolated ganglia. Conversely, a rise of water table leads to an upward migration of LNAPLs resulting in the entrapment of LNAPLs and air by snap-off or bypassing mechanism in smear zone below the groundwater table (Chatzis et al. 1983; Kechavarzi et al. 2005). The smear zone can be characterized by this vertical distribution of LNAPLs in both the unsaturated and saturated zones (Ostendorf et al. 1993) which has received growing attention in recent years (Lakshmi et al. 1998).

The entrapped air in saturated zone provides additional oxygen to LNAPL-degrading microbes. On the other hand, the entrapped LNAPLs reduce the free-phase pool and thus mitigate the likelihood of the pure LNAPLs migration to down-gradient receptors (Fry et al. 1997). Also, the pulse of oxygen introduced by lowering the water table exposes the microbes to the air in the soil pore spaces and enhances biodegradation without the injection of oxygen. At the same time, entrapment of LNAPLs increases their water interfacial area resulting in an enhanced dissolution of the hydrocarbons and hence, enlargement of plume size migrating in the direction of water flow (Miller et al. 1990). Nevertheless, the dissolution process of LNAPLs as a result of groundwater flow in saturated zone is by far considered as the main limiting factor of the contaminant removal from the source zone (Abriola 1989; Powers et al. 1991; Kamon et al. 2006). Furthermore, the wider spreading of LNAPLs in response to the falling and rising of water table exposes them to more microorganisms. The rise of water level also exposes the upper dryer regions of a polluted site to the moisture necessary to sustain microbial metabolism and growth.

Considerable air entrapment and subsequent increase in dissolved oxygen into groundwater can be an important factor in mitigating the potential risk to aquatic organisms inhabiting in areas of groundwater discharge down-gradient from the pollutant site. Moreover, soil air movement as a result of water table fluctuations results in a convective transport of volatile LNAPLs in the soil gas phase (Mercer and Cohen 1990). This is also reported by Lenhard et al. (1995) who showed a significant diffusive transport of LNAPLs in soil air using numerical and lab experiments. Thus, fate and transport of the accumulated LNAPL pool and its associated discontinuous ganglia/blobs in the smear zone are important considerations in bioremediation of polluted sites due to additional chemical and hydraulic heterogeneity in space and time introduced by the fluctuating water table. 
In earlier studies, water table was taken as static for investigating the fate and transfer of LNAPLs near water table with due consideration of the residual LNAPLs (Fried et al. 1979; Miller et al. 1990). The dissolution of LNAPL in both pool and blobs forms was evaluated analytically by Seagren et al. (1994). The main focus of this study was the enhancement of LNAPL dissolution due to biodegradation and flushing. Later, Powers et al. (1991) reviewed the mass transfer and transport mechanisms for LNAPLs pool and associated residual blobs under constant water table condition. These studies contributed to the understanding of the LNAPLs mass transfer near water table and thus provide some insight into estimating the time needed for complete dissolution of LNAPL pools as well as residual blobs in the unsaturated zone. However, the oversimplified assumptions of steady-state flow and/or static water table conditions rarely exist in the field, particularly in coastal regions.

To account for the non-static condition, Lenhard et al. (1995) and Kaluarachchi and Parker (1992) numerically studied the impact of falling water table on the redistribution of the LNAPLs in the unsaturated zone. Rainwater et al. (1993) conducted a laboratory experiment on biodegradation of diesel fuel in sand columns with and without cyclic manipulation of water table. After 9 weeks of the experiment, columns imposed to dynamic water regime showed less residual diesel due to the enhanced degradation compared to the static case. Similarly, Sinke et al. (1998) examined the impact of water table dynamics on redox conditions and transport of dissolved toluene and 4-nitrobenzoate in a sand column. Significant differences in contaminant transport and redox conditions were observed after repeated fluctuations of the water table within the column. However, these experiments did not accurately reflect the situation commonly encountered in LNAPL-polluted sites, where the principle groundwater flow direction is nearly horizontal and the low relative permeability influences the amount of water flow through the LNAPL source zone.

Lakshmi et al. (1998) proposed a mathematical formulation for evaluating the water table effect on mass loss from LNAPL pool in the smear zone. Though the presence of discontinuous LNAPL blobs and biodegradation was considered, the model was not validated against the field data. Moreover, the model assumptions on blob characterization (shape and size), constant rate of water table dynamics, and dissolved solute concentration made it somewhat oversimplified. Williams and Oostrom (2000) performed an intermediate-scale flow cell experiment with a fluctuating water table to study the effect of entrapped air on dissolved oxygen transfer and transport by taking relative permeability influence into account. Entrapment of air during repeated fluctuations led to significant improvement of dissolved oxygen of the groundwater compared with a system without fluctuations. Later, Oostrom et al. (2006) conducted a 2-D experiment to investigate the migration behavior of two LNAPLs having different viscosity under variable water table conditions. The results of this experiment showed that more viscous mobile LNAPL, subject to variable water table conditions, does not necessarily float on the water table and may not appear in an observation well.

Very few field studies have been conducted in polluted aquifers having variations in water table. Steffy et al. (1995) utilized hydrophobic and hydrophillic tensiometers for field measurements to study the immiscible displacement of gasoline over a fluctuating shallow water table. Their findings revealed a significant difference in the saturation distribution of the LNAPLs above the water table between a falling and rising potentiometric surface. However, no attention was paid to the dissolution and/or biodegradation of gasoline. But, Lee et al. (2001) found rapid biodegradation in a toluenecontaminated aquifer subjected to a water table fluctuation of 2-m amplitude. The water table was changing from one season to another, and their conclusion was based on seasonally varying biodegradation rates. Therefore, it is difficult to judge from their study whether the increase in biodegradation and dissolution occurred as a result of water table dynamics, as there was no suitable non-fluctuating reference system.

To sum up, the dynamic soil moisture and LNAPL regimes in response to a fluctuating water table, and the resulting differences in soil aeration, not only affect the microbial degradation rate but also the transport of soil air and substrate throughout the variably saturated zone. Most of the aforementioned studies considered the dynamic water table factor for investigating the distribution/mass transfer of LNAPLs in the smear zone without taking microbial degradation 
into account. Moreover, a constant rate of fall/rise of water table and/or a longer time period for the fluctuation considered in these studies may not be the case at arid and semi-arid coastal polluted sites. Therefore, further research is needed to understand the influence of realistic water table fluctuations on the fate and transport of LNAPLs in variably saturated zones. Furthermore, integration of the combined impact of soil moisture availability and soil temperature variations due to water table fluctuations, with mass transfer processes may result in wide application of biodegradation. Additionally, consideration of soil heterogeneity of polluted sites will improve the findings of LNAPLs fate and transport under dynamic water table conditions.

\subsection{Temperature and Biodegradation}

The temperature in arid and semi-arid coastal regions undergoes large diurnal and seasonal fluctuations. This considerably influences LNAPLs properties, rate of biodegradation, mass transfer rate, and the activity or survival of degraders (Chablain et al. 1997; Margesin and Schinner 2001). Also, soil temperature affects the soil moisture content and vice versa (JRB 1984).

Bioavailability and solubility of LNAPLs are temperature-dependent (Atlas 1991). Low temperature conditions usually result in increased viscosity, reduced volatilization, and decreased water solubility of LNAPLs, and thus delayed onset of biodegradation process (Margesin and Schinner 2001). An increase in temperature decreases LNAPLs viscosity, thereby affecting the degree of distribution, and an increase in diffusion rates of the organic pollutant. It also decreases adsorption, which makes more organic material available for microorganisms to degrade (JRB 1984). Therefore, an LNAPL release in cold environment seems to be long-term and chronic while the release in warm conditions may result in relatively shorter but more acute pollution. Furthermore, the effect of temperature seems to be more significant on the degradation rate of LNAPL compounds with low water solubility, as solubility and thus bioavailability are more enhanced at elevated temperatures.

Temperature plays a significant role in controlling the nature and extent of microbial metabolisms that are responsible for degradation of hydrocarbons (JRB 1984). Microbial metabolism accelerates with increasing soil temperatures up to an optimum value at which growth is maximal. On the other hand, low soil temperatures reduce the fluidity and permeability of the microbial cellular membrane, which hinders nutrient and contaminant uptake (Corseuil and Weber 1994). Though most of the bacteria present in subsurface environments operate most effectively in the range 20-40 C (Chapelle 2001), a wide variety of hydrocarbons has been shown to be biodegraded under very low or highly elevated temperature conditions (Muller et al. 1998; Margesin and Schinner 1999).

Soil microorganisms can grow at temperatures ranging from sub-zero to more than $100^{\circ} \mathrm{C}$ and are mainly divided into three groups based on the range of temperature: (1) psychrophile, (2) mesophiles, and (3) thermophiles (Chablain et al. 1997; Margesin and Schinner 2001). The psychrophiles grow at temperatures below $20^{\circ} \mathrm{C}$, the mesophiles between $20^{\circ} \mathrm{C}$ and $44^{\circ} \mathrm{C}$, and the thermophiles require growth temperatures above $45^{\circ} \mathrm{C}$ (Stetter 1998). The majority of hydrocarbon degraders is mesophile and is most active in the temperature range of $20-35^{\circ} \mathrm{C}$ (Chambers et al. 1991). In general, higher temperatures are associated with higher enzymatic activity and faster biodegradation rates, up to an optimum value that is species specific. In this range, degradation rates of hydrocarbons can double or triple due to a temperature increase of $10^{\circ} \mathrm{C}$ (Corseuil and Weber 1994). If the temperature rises much beyond the optimum value, proteins, enzymes, and nucleic acids become denatured and inactive, leading the inhibition of biodegradation.

The biodegradation of hydrocarbons in cold environments has been reported extensively in various soil and water ecosystems (Braddock et al. 1997; Margesin 2000; Aislabie et al. 1998; Siron et al. 1995; Delille et al. 1998; Delille and Delille 2000). Conclusions arrived from these studies are reviewed by Margesin and Schinner (1999), Stempvoort and Biggar (2008), and Yang et al. (2009). These studies show that psychrophiles play a significant role in the degradation of pollutants in cold regions. Bioaugmentation of hydrocarbon-contaminated cold sites was also investigated by Margesin and Schinner (1999) and Whyte et al. (1998). They showed that bioaugmentation may result in a shorter hydrocarbon acclimation period and, the indigenous microbial populations degrade hydrocarbons more efficiently.

Similarly, thermophiles bacteria possess substantial potential for degrading the soil-water hydrocarbons, including LNAPLs (Muller et al. 1998). Sorkhoh et 
al. (1993) analyzed several soil samples of hydrocarbon-polluted Kuwaiti desert a couple of years after the Gulf War. This was in a semi-arid zone where the soil temperature frequently exceeds $50^{\circ} \mathrm{C}$ in summers (Khan and Al-Ajmi 1998). They found a population density of thermophilic bacteria from $3 \times 10^{3}$ to $1 \times 10^{7}$ per gram of soil, which shows the prospectus of bioremediation under such an extreme environment. Similarly, Radwan et al. (1995) demonstrated the presence and significance of indigenous hydrocarbon-degrading bacteria for treating the polluted desert soil. In these studies, authors provided no exact indication of pollutants concentration with time.

A mixture of thermophilic aerobic bacteria, mainly comprising Pseudomonas species, was successfully used by Lugowski et al. (1997) to degrade various components of LNAPLs containing wastewater at a constant temperature of $40-42^{\circ} \mathrm{C}$. Furthermore, the aerobic bacteria used by Lugowski et al. (1997) were used along with other thermophiles by Taylor et al. (1998) for thermally enhanced in situ remediation of a polluted soil. The authors coupled the thermal treatment (using dynamic underground stripping heating) with in situ bioremediation of the soil to target BTEX contaminants. The targeted soil volume was first heated to vaporize a part of the trapped pollutants followed by vacuum extraction. The soil temperature was observed between $70^{\circ} \mathrm{C}$ and $50^{\circ} \mathrm{C}$ for 2 months after the heat treatment. This enabled thermophilic bacteria to metabolize the lower concentration BTEX compounds in the soil. Schiewer and Niemeyer (2006) showed that higher temperatures increase the biodegradation rate in dieselcontaminated soil from two Alaskan sites. The researchers concluded that a temperature of $6^{\circ} \mathrm{C}$ was sufficient to achieve efficient treatment if all other potentially limiting factors such as oxygen, water content, and nutrient supply were addressed.

Controlling the soil temperature in the field is quite difficult, but can be modified by regulating the incoming and outgoing radiation or by changing the thermal properties of the soil surface. Vegetation plays a significant role in controlling soil temperature because of insulation properties of plant cover (Radwan et al. 1998). Barren soil, unprotected from direct rays of sun, becomes very warm during the hottest part of the day, but also loses its heat rapidly at night and during colder seasons. In the winter, the vegetation acts as an insulator to reduce heat loss from the soil. On the other hand, during the summer months, a well-vegetated soil does not become as warm as a bare soil. Moreover, plants may be used to promote microbial restoration in rhizosphere of LNAPL-contaminated lands (Aprill and Sims 1990; Narayanan et al. 1995; Mathur and Yadav 2009). Also, thermal properties of soil can be regulated by the use of mulches, irrigation, and compaction.

\section{Conclusions and Research Needs}

Biodegradation of various LNAPL-contaminated soil-water systems has been studied under various conditions of low and elevated temperatures, fluctuating water table, and varying soil moisture content. A significant observed biodegradation of LNAPLs under aforesaid conditions emphasizes the metabolic capabilities of microorganisms to decontaminate LNAPL-polluted lands in (semi)-arid coastal environment. However, the impacts of these environmental factors have been often studied separately instead of quantifying their integrated influences on fate and transport of LNAPLs. The environmental factors relevant to arid and semi-arid coastal regions do not function independently, and a change in one shall influence a change in the others. Therefore, the investigation of biodegradation must be performed under a combination of varying environmental factors along with their associated extremes relevant to arid and semi-arid coastal regions.

Similarly, correlations between two environmental factors pertaining to biodegradation can provide guidelines for customizing site-limiting conditions more effectively. For instance, sensitivity of biodegradation to soil moisture may increase/decrease with increasing soil temperature. Furthermore, sensitivity of biodegradation to soil moisture may increase/decrease with decreasing soil moisture content. Such biodegradation correlations between soil environmental factors can be useful for planning water recharge scheduling of polluted lands for maintaining adequate aeration, controlling soil moisture, temperature, and nutrients availability in desirable range to enhance the process of degradation.

Considering the impact of cyclic short-term (i.e., diurnal) variability in top soil environment on the rate of biodegradation would further enhance the investigation in order to obtain a more realistic and widely 
applicable estimate of biodegradation. The soil properties of the polluted land should be identified to predict potential migration of pollutants and for manipulating the soil characteristics for enhancing the land treatment. A consideration of soil characteristics with prevailing environmental parameters will provide some suggestions for manipulating (i.e., tilling, water recharge) the top surface to maintain proper soil moisture, soil temperature, and oxygen supply in vadose zone. Because many LNAPL compounds often coexist with each other in subsurface environment, more studies are needed to investigate the substrate interactions between more than one compound along with their degradation potential in mixtures under site-specific conditions.

Acknowledgments We acknowledge the King Abdullah University of Science and Technology (KAUST) for providing the financial support to this research as part of the SOWACOR project. The authors are also thankful to Department of Science and Technology (DST), India, for extending the financial aid in form of the Ramanujan research award.

Open Access This article is distributed under the terms of the Creative Commons Attribution Noncommercial License which permits any noncommercial use, distribution, and reproduction in any medium, provided the original author(s) and source are credited.

\section{References}

Abriola, L. M. (1989). Modeling multiphase migration of organic chemicals in groundwater systems: A review and assessment. Environmental Health Perspectives, 83, 117-143.

Airoldi, C. A. G. S. P. (1999). The influence of moisture on microbial activity of soils. Thermochimica Acta, 332, 71-74.

Aislabie, J., McLeod, M., \& Fraser, R. (1998). Potential for biodegradation of hydrocarbons in soil from the Ross Dependency, Antarctica. Applied Microbiology and Biotechnology, 49, 210-214.

Alvarez, P. J. J., \& Illman, W. A. (2006). Bioremediation and natural attenuation, process fundamentals and mathematical models. Wiley-Interscience, ISBN-10 0-471-65043-9.

Allard, A. S., \& Neilson, A. H. (1997). Bioremediation of organic waste sites: a critical review of microbiological aspects. International Biodeterioration and Biodegradation, 39, 253-285.

Andre, L., Kedziorek, M. A. M., Bourg, A. C. M., Haeseler, F., \& Blanchet, D. (2009). A novel experimental procedure to investigate the biodegradation of NAPL under saturated conditions. Journal of Hydrology, 370, 1-8.

Andreoni, V., \& Gianfreda, L. (2007). Bioremediation and monitoring of aromatic-polluted habitats. Applied Microbiology and Biotechnology, 76, 287-308.
Aprill, W., \& Sims, R. C. (1990). Evaluation of the use of prairie grasses for stimulating polycyclic aromatic hydrocarbon treatment in soil. Chemosphere, 20, 253365.

Arora, H. S., Cantor, R. R., \& Nemeth, J. C. (1982). Land treatment: A viable and successful method of treating petroleum industry wastes. Environmental International, 7, 285-291.

Atlas, R. M. (1991). Microbial hydrocarbon degradation and bioremediation of oil spills. Journal of Chemical Technology and Biotechnology, 52, 149-156.

Braddock, J. F., Ruth, M. L., Walworth, J. L., \& McCarthy, K. A. (1997). Enhancement and inhibition of microbial activity in hydrocarbon- contaminated arctic soils: implications for nutrient amended bioremediation. Environmental Science \& Technology, 31, 2078-2084.

Bosma, T. N. P., Middeldorp, P. J. M., Schraa, G., \& Zehnder, A. J. B. (1997). Mass transfer limitation of biotransformation: quantifying bioavailability. Environmental Science \& Technology, 31, 248-252.

Bossert, I., Kachel, W. M., \& Bartha, R. (1984). Fate of hydrocarbons during oily sludge disposal in soil. Applied and Environmental Microbiology, 47, 763-767.

Chablain, P. A., Philippe, G., Groboillot, A., Truffaut, N., \& Guespin-Michel, J. F. (1997). Isolation of a soil psychrotrophic toluenedegrading Pseudomonas strain: influence of temperature on the growth characteristics on different substrates. Research in Microbiology, 148, 153-161.

Chambers, C. D., Willis, J., Gitipour, S., Zieleniewski, J. L., Rickabaugh, J. F., Mecca, M. I., et al. (1991). In situ treatment of hazardous waste contaminated soils, second edition (pollution technology review). Park Ridge: Noyes Data Corporation.

Chapelle, F. H. (2001). Ground-water microbiology and geochemistry (p. 477). New York: John Wiley \& Sons.

Chatzis, I., Morrow, N. R., \& Lim, H. T. (1983). Magnitudeand detailed structure of residual oil saturation. Society of Petroleum Engineering Journal, 23, 311-325.

Chen, M. M., Zhu, Y. G., Su, Y. H., Chen, B. D., Fu, B. J., \& Marschner, P. (2007). Effects of soil moisture and plant interactions on the soil microbial community structure. European Journal of Soil Biology, 43, 31-38.

Clement, T. P., Johnson, C. D., Sun, Y., Klecka, G. M., \& Bartlett, C. (2000). Natural attenuation ofchlorinated ethene compounds: model development and field-scale application at the Dover site. Journal of Contaminant Hydrology, 42, 113-140.

Corseuil, H., \& Weber, W. (1994). Potential biomass limitations on rates of degradation of monoaromatic hydrocarbons by indigenous microbes in subsurface soils. Water Research, 28, 1415-1423.

CONCAWE. (1998). Heavy fuel oils, product dossier no. 98/ 109, Prepared by CONCAWE's Petroleum Products and Health Management Groups, Brussels, pp. 53

Cunningham, J. A., Rahme, H., Hopkins, G. D., Lebron, C., \& Reinhard, M. (2001). Enhanced in situ bioremediation of BTEX-contaminated groundwater by combined injection of nitrate and sulphate. Environmental Science \& Technology, 35, 1663-1670. 
Daifullah, A. A. M., \& Girgis, B. S. (2003). Impact of surface characteristics of activated carbon on adsorption of BTEX. Colloids and Surfaces. A, 214, 181-193.

Davis, J. W., \& Madsen, S. (1996). Factors affecting the biodegradation of toluene in soil. Chemosphere, 33(1), 107-130.

Delille, D., \& Delille, B. (2000). Field observations on the variability of crude oil impact in indigenous hydrocarbondegrading bacteria from sub-Antarctic intertidal sediments. Marine Environmental Research, 49, 403-417.

Delille, D., Bassères, A., \& Dessommess, A. (1998). Effectiveness of bioremediation for oil-polluted Antarctic seawater. Polar Biology, 19, 237-241.

Dibble, J. T., \& Bartha, R. (1979). Effect of environmental parameters on parameters on the biodegradation of oil sludge. Applied and Environmental Microbiology, 37, 729-739.

Dupont, R. R., Doucette, W. J., Hinchee, R. E., et al. (1991). Assessment of in situ bioremediation potential and application of bioventing at a fuel-contaminated site. In R. F. Olfenbuttel (Ed.), In situ bioreclamation (pp. 262282). Stoneham: Butterworth-Heinemann.

English, C. W., \& Loehr, R. C. (1991). Degradation of organic vapors in unsaturated soil. Journal of Hazardous Material, $28,55-64$

Estrellea, M. R., Brusseau, M. L., Maier, R. S., Pepper, I. L., Wierenga, P. J., \& Miller, R. M. (1993). Biodegradation, sorption, and transport of 2, 4-dichlorophenoxyacetic acid in saturated and unsaturated soils. Applied and Environmental Microbiology, 59, 4266-4273.

Farhadian, M., Vachelard, C., Duchez, D., \& Larroche, C. (2008). In situ bioremediation of monoaromatic pollutants in groundwater: A review. Bioresource Technology, 99, 5296-5308.

Fiorenza, S., \& Ward, C. H. (1997). Microbial adaptation to hydrogen peroxide and biodegradation of aromatic hydrocarbons. Journal of Industrial Microbiology \& Biotechnology, 18, 140-151.

Fried, J. J., Munter, P., \& Zilliox, L. (1979). Ground-water pollution by transfer of oil hydrocarbons. Groundwater, 17 (6), 586-594.

Fry, V. A., Selker, J. S., \& Gorelick, S. M. (1997). Experimental investigations for trapping oxygen gas in saturated porous media for in situ bioremediation. Water Resources Research, 33(12), 2687-2696.

Griffin, D. M. (1981). Water potential as a selective factor in the microbial ecology of soils. In J. F. Parr, W. R. Gardner, \& L. F. Elliott (Eds.), Water potential relations in soil microbiology (pp. 141-151). Madison: Soil Science Society of America.

Griffiths, R. I., Whiteley, A. S., O’Donnell, A. G., \& Bailey, M. J. (2003). Physiological and community response of established grassland bacterial populations to water stress. Applied and Environmental Microbiology, 69, 6961-6968.

Harms, H. (1996). Bacterial growth on distant naphthalene diffusing through water, air, watersaturated, and unsaturated porous media. Applied and Environmental Microbiology, 62, 2286-2293.

Harris, R. F. (1981). Effect of water potential on microbial growth and activity. In J. F. Parr, W. R. Gardner, \& L. F. Elliott (Eds.), Water potential relations in soil microbiol- ogy. SSSA special publication number 9 (pp. 23-95). Madison: Soil Science Society of America.

Holden, P. A., Halverson, L. J., \& Firestone, M. K. (1997). Water stress effects on toluene biodegradation by Pseudomonas putid. Biodegradation, 8, 143-151.

Holden, P. A., Hersman, L. E., \& Firestone, M. K. (2001). Water content mediated microaerophilic toluene biodegradation in arid Vadose zone materials. Microbial Ecology, 42, 256-266.

Holman, H. Y., \& Tsang, Y. W. (1995). Influence of soil moisture on biodegradation of petroleum hydrocarbons. In R. E. Hinchee, R. N. Miller, \& P. C. Johnson (Eds.), In situ aeration: air sparging, bioventing, and related remediation processes (pp. 323-332). Colombus: Battelle.

Huddleston, R. L., Bleckmann, C. A., Wolfe, J. R. (1985). Land treatment: Biological degradation process. In Loehr, R. C., \& Mlina, J. F. Jr (Eds.), Land Treatment-A Hazardous Waste Management Alternative, Water Resources Symposium No. 13, Austin: Center for Research in Water Resources, Bureau of Engineering, University of Texas. pp. 1-37.

Johnston, C. D., Rayner, J. L., Patterson, B. M., \& Davis, G. B. (1998). Volatilisation and biodegradation during air sparging of dissolved BTEX-contaminated groundwater. Journal of Contaminant Hydrology, 33, 377-404.

JRB. (1984). Summary report: Remedial response at hazardous waste sites, prepared for municipal environment research laboratory. EPA Report No. 625/6-82-006

Juhasz, A. L., Megharaj, M., \& Naidu, R. (2000). Bioavailability: The major challenge to bioremediation of organically contaminated soil, remediation engineering of contaminated soil. New York: Marcel Dekker.

Kaluarachchi, J. J., \& Parker, J. C. (1992). Multiphase flow with a simplified model for oil entrapment. Transport in Porous Media, 7, 1-14.

Kamon, M., Li, Y., Flores, G., Inui, T., Katsumi, T. (2006). Experimental and numerical study on migration of LNAPL under the influence of fluctuating water table in subsurface, Annuals of Disas. Prev. Res. Inst., Kyoto Univ., No. 49 B.

Kechavarzi, C., Soga, K., \& Illangasekare, T. H. (2005). Twodimensional laboratory simulation of LNAPL infiltration and redistribution in the Vadose Zone. Journal of Contaminant Hydrology, 76(3-4), 211-233.

Khan, N. Y., \& Al-Ajmi, D. (1998). Post-war imperatives for the sustainable management of the Gulf ecosystem. Environmental International, 24, 239-248.

Kieft, T. L., Soroker, E., \& Firestone, M. K. (1987). Microbial biomass response to a rapid increase in water potential when dry soil in wetted. Soil Biology and Biochemistry, 19, 119-126.

Konopka, A., \& Turco, R. (1991). Biodegradation of organic compounds in vadose zone and aquifer sediments. Applied Environmental Microbiololgy, 57, 2260-2268.

Lakshmi, N. R., Han, W., \& Banks, M. K. (1998). Mass loss from LAPL pools under fluctuating water table conditions. Journal of Environmental Engineering, 124(12), 11711177.

Lee, C. H., Lee, J. Y., Cheon, J. Y., \& Lee, K. K. (2001). Attenuation of petroleum hydrocarbons in smear zones: A case study. Journal of Environmental Engineering, 127(7), 639-647. 
Lenhard, R. J., Oostrom, M., Simmon, C. S., \& White, M. D. (1995). Investigation of density-dependent gas advection of trichloroethylene: Experiment and a model validation exercise. Journal of Contaminant Hydrology, 19, 47-67.

Lieberman, H. A., Rieger, M. M., Banker, G. S. (1998). Pharmaceutical dosage forms; Disperse systems, Eds. Marcel Dekker, New York, 2nd ed., 559 pp

Lin, B., Van Verseveld, H. W., \& Roling, W. F. (2002). Microbial aspects of anaerobic BTEX degradation. Biomedical and Environmental Sciences, 15, 130-144.

Lugowski, A. J., Palamteer, G. A., Boose, T. R., Merriman, J. E. (1997). Biodegradation process for detoxifying liquid streams. Patent US5656169, August 12.

Lyman, W. J., Reidy, P. J., \& Levy, B. (1992). Mobility and degradation of organic contaminants in subsurface environments (p. 395). Chelsea: C.K. Smoley.

Margesin, R. (2000). Potential of cold-adapted microorganisms for bioremediation of oil-polluted alpine soils. International Biodeterioration and Biodegradation, 46, 3-10.

Margesin, R., \& Schinner, F. (1999). Biological decontamination of oil spills in cold environments. Journal of Chemical Technology and Biotechnology, 74, 381-389.

Margesin, R., \& Schinner, F. (2001). Biodegradation and bioremediation of hydrocarbons in extreme environments. Applied Microbiology and Biotechnology, 56(5), 650-663.

Marinelli, F., \& Durnford, D. S. (1996). LNAPL thickness in monitoring wells considering hysteresis and entrapment. Ground Water, 34(3), 405-414.

Marrin, D. L., \& Kerfoot, H. B. (1988). Soil-gas surveying techniques. Environmental Sciences Technology, 22(7), 740-745.

Mathur, S., \& Yadav, B. K. (2009). Phytoextraction modeling of heavy metal (Lead) contaminated site using Maize (Zea mays). Practice Periodical of Hazardous Toxic and Radioactive Waste Management, 13(4), 229-238.

Mascolo, G., Ciannarella, R., Balest, L., \& Lopez, A. (2007). Effectiveness of UV-based advanced oxidation processes for the remediation of hydrocarbon pollution in the groundwater: A laboratory investigation. Journal of Hazardous Material, 152(3), 1138-1145.

Meikle, A., Aminhanjani, S., Glover, L. A., Killham, K., \& Prosser, J. I. (1995). Matric potential and the survival and activity of a Pseudomonas fluorescens inoculum in soil. Soil Biology and Biochemistry, 27, 881-892.

Merchuk, J. C., \& Ansejo, J. A. (1995). The Monod equation and mass transfer. Biotechnology and Bioengineering, 45, 91-94.

Mercer, J. W., \& Cohen, R. M. (1990). A review of immiscible fluids in the subsurface: Properties, models, characterization, and remediation. Journal of Contaminant Hydrology, 6, 107-163.

Mikszewski, A. (2004). Emerging technologies for the in situ remediation of PCB-contaminated soils and sediments: Bioremediation and nanoscale zero-valent Iron, Status Report prepared for the U.S. EPA Technology Office under a Technology Innovation Program Washington, DC.

Miller, C. T., Poirier-McNeil, M. M., \& Mayer, A. S. (1990). Dissolution of trapped nonaqueous phase liquids: Mass transfer characteristics. Water Resources Research, 26(11), 2783-2796.
Morgan, P., \& Watkinson, R. J. (1992). Factors limiting the supply and efficiency of nutrient and oxygen supplements for the in situ biotreatment of contaminated soil and groundwater. Water Research, 26, 73-78.

Monod, J. (1949). The growth of bacterial cultures. Annual Review of Microbiology, 3, 371-394.

Muller, R., Antranikian, G., Maloney, S., \& Sharp, R. (1998). Thermophilic degradation of environmental pollutants. In G. Antranikian (Ed.), Biotechnology of extremophiles. (Advances in Biochemical Engineering/Bio-technology, vol 61) (pp. 155-169). Berlin Heidelberg New York: Springer.

Narayanan, M., Davis, L. C., \& Erickson, L. E. (1995). Fate of volatile chlorinated organic compounds in a laboratory chamber with alfalfa plants. Environmental Science \& Technology, 29, 2437-2444.

Norris, R. D., Hinchee, R. E., Brown, R., McCarty, P. L., Semprini, L., Wilson, J. T., et al. (1994). Handbook of bioremediation. Boca Raton: Lewis.

Odum, E. P. (1971). Fundamentals of ecology. Philadelphia: The W. B. Saunders.

Oostrom, M., Hofstee, C., \& Wietsma, T. W. (2006). Behavior of a viscous LNAPL under fluctuating water table conditions. Soil and Sediment Contamination, 15, 543-564.

Ostendorf, D. W., Richards, R. J., \& Beck, F. P. (1993). LNAPL retention in sandy soil. Ground Water, 31(2), 285-292.

Papendick, R. I., \& Campbell, G. S. (1981). Theory and measurement of water potential. In J. F. Parr, W. R. Gardner, \& L. F. Elliott (Eds.), Water potential relations in soil microbiology (pp. 1-22). Madison: Soil Science Society of America.

Petersen, L. W., Rolston, D. E., Moldrup, P., \& Yamaguchi, T. (1994). Volatile organic vapor diffusion and adsorption in soils. Journal of Environmental Quality, 23, 799-805.

Powers, S. E., Loureiro, C. O., Abriola, L. M., \& Weber, W. J. (1991). Theoretical study of the significance of nonequilibrium dissolution of nonaqueous-phase liquids in subsurface systems. Water Resources Research, 27(4), 463-477.

Pramer, D., \& Bartha, R. (1972). Preparation and processing of soil samples for biodegradation studies. Environmental Letters, 2, 217-224.

Radwan, S. S., Sorkhoh, N. A., Fardoun, F., \& Al-Hasan, R. H. (1995). Soil management enhancing hydrocarbon biodegradation in the polluted Kuwaiti desert. Applied Microbiology and Biotechnology, 44, 265-270.

Radwan, S. S., Al-Awadhi, H., Sorkhoh, N. A., \& El-Nemr, I. M. (1998). Rhizospheric hydrocarbon-utilizing microorganisms as potential contributors to phytoremediation for the oily Kuwaiti desert. Microbiological Research, 153, 247-251.

Rainwater, K., Mayfield, M. P., Heintz, C., \& Claborn, B. J. (1993). Enhanced in situ biodegradation of diesel fuel by cyclic vertical water table movement: Preliminary Studies. Water Environment Research, 65(6), 717-725.

Ranck, J. M., Bowman, R. S., Weeber, J. L., Katz, L. E., \& Sullivan, E. J. (2005). BTEX removal from produced water using surfactant-modified zeolite. Journal of Environmental Engineering, 131, 434-442.

Riser-Roberts, E. (1998). Remediation of petroleum contaminated soils: biological, physical, and chemical processes (p. 542). Boca Raton: CRC-Press LLC. 
Rockne, K. J., \& Reddy, K. R. (2003). Bioremediation of contaminated sites, Invited Theme Paper, International eConference on Modern Trends in Foundation Engineering: Geotechnical Challenges and Solutions, Indian Institute of Technology, Madras, India.

Rosenberg, E., Lagmann, R., Kushmaro, A., Taube, R., Adler, R., \& Ron, E. Z. (1992). Petroleum bioremediation-A multiphase problem. Biodegradation, 3, 337-350.

Ryan, J. R., Hanson, M. L., \& Loehr, R. C. (1983). Land treatment practices in the petroleum industry. Land treatment, hazardous management alternative. Water Resources Symposium, 13, 319-345.

Schiewer, \& Niemeyer. (2006). Soil heating and optimized nutrient addition for accelerating bioremediation in cold climates. Polar Record, 42, 23-31.

Seagren, E. A., Rittmann, B. E., \& Valocchi, A. J. (1994). Quantitative evaluation of the enhancement of NAPL-pool dissolution by flushing and biodegradation. Environmental Science \& Technology, 28(5), 833-839.

Simoni, S. F., Schafer, A., Harms, H., \& Zehnder, A. J. B. (2001). Factors affecting mass transfer limitation of biodegradation in saturated porous media. Journal of Contaminant Hydrology, 50(1-2), 99-120.

Sims, J. L., Sims, R. C., DuPont, R. R., Matthews, J. E., Russell, H. H. (1993). In situ bioremediation of contaminated unsaturated subsurface soils, U.S. Environmental Protection Agency, Office of Solid Waste and Emergency Response, Washington, DC.

Sinke, A. J. C., Dury, O., \& Zobrist, J. (1998). Effects of a fluctuating water table: Column study on redox dynamics and fate of some organic pollutants. Journal of Contaminant Hydrology, 33, 231-246.

Singer, M. E., \& Finnerty, W. R. (1984). Microbial metabolism of straight-chain and branched Alkenes, Petrolium Microbiology. In Atlas R (Ed.), (p. 60).

Siron, R., Pelletier, E., \& Brochu, C. (1995). Environmental factors influencing the biodegradation of petroleum hydrocarbons in cold seawater. Archives of Environmental Contamination and Toxicology, 28, 406-416.

Slater, J. H. (1979). Microbial population and community dynamics. In J. M. Lynch \& N. J. Poole (Eds.), Microbial ecology: A conceptual approach (pp. 45-63). Oxford: Blackwell Scientific.

Sommers, L. E., Gilmour, C. M., Wildung, R. E., \& Beck, S. M. (1981). The effect of water potential on decomposition processes in soils. In J. F. Parr, W. R. Gardner, \& L. F. Elliott (Eds.), Water potential relations in soil microbiology (pp. 97-117). Madison: Am Soc Agron.

Sorkhoh, N. A., Ibrahim, A. S., Ghannoum, M. A., \& Radwan, S. S. (1993). High-temperature hydrocarbon degradation by Bacillus stearothermophilus from oil-polluted Kuwait desert. Applied Microbiology and Biotechnology, 39(1), 123-126.

Steffy, D. A., Johnston, C. D., Barry, D. A. (1995). A field study of the vertical immiscible displacement of LNAPL associated with a fluctuating water table. In Kovar, K., \& Krasny, J. (Eds.), Groundwater quality: Remediation and protection. Proc. Prague Conference, May, IAHS Publ. 225, 49-57.

Stetter, K. O. (1998). Hyperthermophiles: isolation, classification, and properties. In K. Horikoshi \& W. D. Grant (Eds.),
Extremophiles: microbial life in extreme environments (pp. 1-24). New York: Wiley-Liss.

Stempvoort, D. V., \& Biggar, K. (2008). Potential for bioremediation of petroleum hydrocarbons in groundwater under cold climate conditions: A review. Cold Regions Science and Technology, 53, 16-41.

Taylor, S. A., \& Ashcroft, G. L. (1972). Physical edaphology: The physics of irrigated and nonirrigated soils. San Francisco: W.H. Freeman and Company.

Taylor, T. R., Jackson, K. J., Duba, A. G., Chen, C. I. (1998). In situ thermally enhanced biodegradation of petroleum fuel hydrocarbons and halogenated organic solvents. Patent US5753122, May 19.

Thomas, L. K., Amy, P. S., Brockman, F. J., Fredrickson, J. K., Bjornstad, B. N., \& Rosacker, L. L. (1993). Microbial abundance and activities in relation to water potential in the vadose zones of arid and semiarid sites. Microbial Ecology, 26, 59-78.

Tsao, C. W., Song, H. G., \& Bartha, R. (1998). Metabolism of benzene, toluene, and xylene hydrocarbons in soil. Applied and Environmental Microbiology, 64, 4924-4929.

Turco, R. F., \& Sadowsky, M. J. (1995). The microflora of bioremediation. In Bioremediation: Science and applications, soil science special Publication No. 43 Soil Science Society of America, Madison, Wisconsin, pp. 87-102

USEPA (1998). Guidelines for ecological risk assessment, risk assessment forum, Washington, DC, EPA/630/R095/002F.

USEPA (2006). In situ and ex situ biodegradation technologies for remediation of contaminated sites, EPA/625/R-06/015.

Van Hamme, J. D., Singh, A., \& Ward, O. P. (2003). Recent advances in petroleum microbiology. Microbiology and Molecular Biology Review, 67, 503-549.

Venosa, A. D., Lee, K., Suidan, M. T., Garcia-Blanco, S., Cobanli, S., Moteleb, M., et al. (2002). Bioremediation and biorestoration of a crude oil-contaminated freshwater wetland on the St. Lawrence River. Bioremediation Journal, 6(3), 261-281.

Whyte, L. G., Hawari, J., Zhou, E., Bourbonniere, L., Inniss, W. E., \& Greer, C. W. (1998). Biodegradation of variablechain-length alkanes at low temperatures by a psychrotrophic Rhodococcus sp. Applied and Environmental Microbiology, 64, 2578-2584.

Wiedemeier, T. H., Rifai, H. S., Newell, C. J., \& Wilson, J. T. (1999). Natural attenuation of fuels and chlorinated solvents in the subsurface (p. 617). New York: John Wiley \& Sons.

Williams, M. D., \& Oostrom, M. (2000). Oxygenation of anoxic water in a fluctuating water table system: An experimental and numerical study. Journal of Hydrology, 230, 70-85.

Wise, D. L., Debra, J., Trantolo, Edward J. Cichon, Hilary I. Inyang and Ulrich Stottmeister. Marcell Dekker (2000). Remediation Engineering of Contaminated Soils, CRC Press, New York, ISBN 0-8247-0332-4.

Yadav, B. K., Mathur, S., \& Siebel, M. A. (2009). Soil moisture flow modeling with water uptake by plants (wheat) under varying soil and moisture conditions. Journal of Irrigation and Drainage Engineering, 135(3), 375-381.

Yadav, B. K., Hassanizadeh, S. M., Kleingeld, P. J. (2010). Biodegradation of BTEX under Varying Soil Moisture and Temperature Conditions. In: The first international confer- 
ence on Frontiers in Shallow Subsurface Technology, held at TU Delft, The Netherlands on January 20-22.

Yang, X., Beckmann, D., Fiorenza, S., \& Niedermeier, C. (2005). Field study of pulsed air sparging for remediation of petroleum hydrocarbon contaminated soil and groundwater. Environmental Science \& Technology, 39, 72797286.

Yang, S. Z., Jin, H. J., Wei, Z., He, R. X., Ji, Y. J., Li, X. M., et al. (2009). Bioremediation of oil spills in cold environments: A review. Pedosphere, 19, 371-381.

Zhang, M. H., Geng, S., \& Ustin, S. L. (1998a). Quantifying the agricultural landscape and assessing spatio-temporal patterns of precipitation and groundwater use. Landscape Ecology, 13(1), 37-53.
Zhang, Q., Davis, L. C., \& Erickson, L. E. (1998b). Effect of vegetation on transport of groundwater and nonaqueous phase liquid contaminants. Journal of Hazardous Substance Research, I, 8-1-8-20.

Zwick, T. C., Leeson, A., Hinchee, R. E., Hoeppel, R. E., Bowling, L. (1995). Soil moisture effects during bioventing in fuel-contaminated arid soils. In Third International In Situ and On-Site Bioreclamation Symposium, In Situ Aeration vol. 3, Batelle Press, San Diego, CA (2).

Zhu, X., Venosa, A. D., Suidan, M. T. (2004). Literature review on the use of commercial bioremediation agents for cleanup of oil-contaminated estuarine environments. U.S. Environmental Protection Agency Cincinnati, OH 45268 . 